\title{
Calcium intake and risk of primary hyperparathyroidism in women: prospective cohort study
}

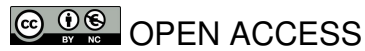

\author{
Julie M Paik instructor and attending physician ${ }^{12}$, Gary C Curhan professor and attending \\ physician $^{123}$, Eric N Taylor assistant professor and attending physician ${ }^{14}$
}

${ }^{1}$ Channing Division of Network Medicine, Department of Medicine, Brigham and Women's Hospital, Harvard Medical School, Boston, MA 02115, USA; ${ }^{2}$ Renal Division, Department of Medicine, Brigham and Women's Hospital; ${ }^{3}$ Department of Epidemiology, Harvard School of Public Health, Boston; ${ }^{4}$ Division of Nephrology and Transplantation, Maine Medical Center, Portland, ME, USA

\begin{abstract}
Objective To examine the association between calcium intake and risk of primary hyperparathyroidism in women.

Design Prospective cohort study.

Setting Nurses' Health Study I, which originally recruited participants from the 11 most populous states in the United States.

Participants 58354 female registered nurses enrolled in the Nurses' Health Study I aged 39-66 years in 1986 and with no history of primary hyperparathyroidism. Calcium intake was assessed every four years using semiquantitative questionnaires on food frequency.

Main outcome measure Incident primary hyperparathyroidism, confirmed by medical record review.
\end{abstract}

Results During 22 years of follow-up, we recorded 277 incident cases of primary hyperparathyroidism. Women were divided into five equal groups, according to intake of dietary calcium. After adjusting for age, body mass index, race, and other factors, the relative risk of primary hyperparathyroidism for women in the group with the highest intake of dietary calcium was 0.56 ( $95 \%$ confidence interval 0.37 to $0.86, P=0.009$ for trend), compared with the group with the lowest intake. The multivariable relative risk of primary hyperparathyroidism for women taking more than $500 \mathrm{mg} /$ day of calcium supplements compared with no calcium supplements was 0.41 (95\% confidence interval 0.29 to 0.60 , $\mathrm{P}<0.001$ for trend). Analyses restricted to participants with regular physical exams did not significantly change the association between calcium intake and risk of primary hyperparathyroidism.

Conclusion Increased calcium intake is independently associated with a reduced risk of primary hyperparathyroidism in women.

\section{Introduction}

Primary hyperparathyroidism is the most common cause of hypercalcemia ${ }^{1}$ and the third most common endocrine disorder, with 100000 new cases in the United States each year. ${ }^{2}$ Up to $2 \%$ of postmenopausal women could have this condition. ${ }^{34}$ Primary hyperparathyroidism is characterized by hypercalcemia with a high or insufficiently suppressed level of parathyroid hormone, and is caused by a solitary parathyroid adenoma in $85-90 \%$ of patients. ${ }^{56}$ Associated morbidities and costly sequelae include decreased bone mineral density, fractures, and kidney stones. ${ }^{78}$ However, little is known about risk factors for primary hyperparathyroidism. ${ }^{9}$ Monogenic disorders (such as multiple endocrine neoplasia I and II $)^{10}$ account for fewer than $5 \%$ of cases, ${ }^{11}$ and neck irradiation also accounts for only a small fraction of cases. ${ }^{12}$

Because the parathyroid adenoma of sporadic primary hyperparathyroidism is monoclonal, ${ }^{13-15}$ factors that chronically stimulate parathyroid hormone and increase the probability of a parathyroid cell undergoing a somatic mutation and subsequent clonal proliferation could increase the risk for primary hyperparathyroidism. ${ }^{114}{ }^{16}$ Calcium intake is known to influence parathyroid hormone level ${ }^{17-22}$ and therefore could be important in the pathogenesis of primary hyperparathyroidism. However, no study to date has prospectively explored the relation between calcium intake and risk of developing primary hyperparathyroidism.

To examine the association between calcium intake and the risk of incident primary hyperparathyroidism, we conducted a prospective study of 58354 women in the Nurses' Health Study I without history of primary hyperparathyroidism at baseline.

\section{Methods}

\section{Study population}

The Nurses' Health Study I is an ongoing, prospective cohort study which began in 1976, enrolling 121700 female registered nurses between 30 and 55 years of age and residing in 11 US states. The cohort is followed by using questionnaires mailed every two years that ask about lifestyle practices and newly diagnosed diseases. The average proportion of participants followed up has been more than $90 \%$. The sample for our 
analysis was limited to the 58354 women who answered either the 2006 or 2008 questionnaires, which included questions on lifetime history of primary hyperparathyroidism. The study protocol was reviewed and approved by the Brigham and Women's Hospital institutional review board.

\section{Assessment of dietary intake}

To assess the participants' diet, we used semiquantitative questionnaires on food frequency that asked about the average intake of more than 130 individual food items and 22 individual beverages during the previous year. The participants were asked to complete food frequency questionnaires in 1986, 1990, 1994, 1998, 2002, and 2006. Intake of specific dietary factors was computed from the reported frequency of consumption of each specified unit of food and from US Department of Agriculture data on the content of the relevant nutrient in specified portions. Nutrient values were adjusted for total energy intake to determine the nutrient composition of the diet independent of the total amount of food eaten. The food frequency questionnaire also asked about the use of calcium supplements, vitamin D supplements, and multivitamins. The intake of supplemental calcium, vitamin A, and vitamin D in multivitamins or in isolated form were determined by the brand, type, and frequency of reported use.

The food frequency questionnaire has been extensively validated. ${ }^{23}$ In a sample of 173 participants in the Nurses' Health Study I, nutrient intake reported on two food frequency questionnaires was compared with four seven-day records kept by the nurses who weighed and measured everything they ate or drank. ${ }^{24}$ The values for the nutrient data on the two food frequency questionnaires and the food diaries were highly correlated, and the degree of reproducibility was not modified by obesity or other personal characteristics. For example, correlation coefficients were 0.81 for skim or low fat milk and 0.94 for yogurt. $^{24}$

\section{Assessment of non-dietary factors}

Age, body mass index, smoking status (never, past, current), physical activity (in metabolic equivalent task scores), history of diabetes, hypertension, diuretic use, menopausal status, and postmenopausal hormone use were ascertained from the biennial questionnaires. Self reported weight was highly reliable $(r=0.97)$ among a subset of participants who underwent direct measurement of their weight. ${ }^{25}$ Physical activity reported on the questionnaires has been previously validated against physical activity diaries $(r=0.79){ }^{26}$ Self reported hypertension ${ }^{27}$ and diabetes ${ }^{28}$ were previously validated in this cohort. Self reported age at menopause and type of menopause were previously validated in the Nurses' Health Study I and shown to be highly accurate. ${ }^{29}$ Race was self reported and categorized in this analysis as white and non-white.

\section{Assessment of cases}

Participants were asked about a diagnosis of hyperparathyroidism on the 2006 and 2008 questionnaires. On the 2008 questionnaire, nurses were also asked about lifetime history of hyperparathyroidism. To identify primary $(v$ secondary) hyperparathyroidism, we subsequently obtained the medical records of all participants who gave consent. We confirmed cases of primary hyperparathyroidism by pathology report of a resected adenoma or by elevated serum concentrations of calcium $(\geq 10.6 \mathrm{mg} / \mathrm{dL} ; 1 \mathrm{mg} / \mathrm{dL}=0.25$ $\mathrm{mmol} / \mathrm{L}$ ) with high or insufficiently suppressed parathyroid hormone $^{30-34}(\geq 50 \mathrm{pg} / \mathrm{mL} ; 1 \mathrm{pg} / \mathrm{mL}=1 \mathrm{ng} / \mathrm{L})$. The medical record confirmation rate was $75 \%$. Cases were rejected after medical record review for a variety of reasons, most commonly incomplete data or identification of secondary hyperparathyroidism from vitamin D deficiency or renal insufficiency.

We included in the analysis only cases of primary hyperparathyroidism that were diagnosed during the 22 years between the date on which the 1986 questionnaire was returned and 31 May 2008. Participants with a history of primary hyperparathyroidism at baseline were excluded from the study.

\section{Statistical analyses}

The study design was prospective; information on diet was collected before the diagnosis of primary hyperparathyroidism. For each participant, we counted person months of follow-up from the date on which the 1986 questionnaire was returned to the date on which primary hyperparathyroidism was diagnosed or death occurred, or 31 May 2008, whichever occurred first. Information on exposures of interest that was recorded in response to the 1986 questionnaire was updated on subsequent questionnaires. We allocated person time of follow-up according to exposure status at the start of each follow-up period. Dividing the cohort into five equal groups of nutrient intake allowed us to examine a wide range of nutrient intake while maintaining enough participants in the highest and lowest categories. If complete information on diet was missing at the start of a time period, the participant was excluded from that time period.

The relative risk - the incidence among women in a particular category of intake divided by the corresponding rate in the comparison category - was used as the measure of association. We used the Mantel extension test to evaluate linear trends across categories of calcium intake. We used a proportional hazards model to simultaneously adjust for several risk factors. The variables considered in these models were age; body mass index ( $<22,22-24.9,25-29.9$, and $\geq 30$ ); race (white or non-white); physical activity level (divided into five equal groups of differing levels); alcohol intake (none, 0.1-4.9, 5-14.9, $\geq 15 \mathrm{~g}$ /day); use of thiazide or loop diuretics (yes or no); supplemental calcium intake (none, 1-500, >500 mg/day); supplemental vitamin D intake (none, 1-400, >400 IU/day); dietary intakes of calcium, vitamin $\mathrm{D}$, vitamin $\mathrm{A}$, and protein (total and animal protein intake); self reported diabetes; self reported hypertension; menopausal status; postmenopausal hormone use; and physical exam during the prior two years. Owing to the high correlation between the dietary intakes of calcium and phosphorus ( $r \geq 0.68$ for all follow-up periods), we excluded phosphorus from the multivariable models. We calculated $95 \%$ confidence intervals for all relative risks. All P values were two tailed.

\section{Results \\ Dietary calcium intake}

During 1475978 person years of follow-up over a 22 year period, we confirmed 277 cases of incident primary hyperparathyroidism. Table $1 \Downarrow$ shows the characteristics of the cohort, divided into five equal groups according to energy adjusted intake of dietary calcium in 1986. For our analyses, however, the updated dietary values were used for each time period. The mean daily intake of vitamin $\mathrm{D}$, magnesium, total protein, animal protein, and vitamin A, and the physical activity level increased with increasing dietary calcium intake. The average daily alcohol intake and the percentage of current smokers decreased with increasing calcium intake. The percentage of nurses with self reported diabetes or hypertension 
or who were taking thiazide diuretics and the mean daily intake of supplemental calcium was similar across the five groups.

After adjusting for age, a higher intake of dietary calcium was associated with a reduced risk of primary hyperparathyroidism (table $2 \Downarrow$ ). The relative risk for women in the group with the highest intake of dietary calcium compared with women with the lowest intake was 0.61 (95\% confidence interval 0.42 to $0.90, \mathrm{P}=0.03$ for trend).

After further adjusting for body mass index, race, smoking status, calcium supplement use, intake of vitamin D, dietary intake of vitamin A and protein, alcohol intake, and diuretic use, the adjusted relative risk for women in the group with the highest intake of dietary calcium compared with women with the lowest intake was 0.56 (95\% confidence interval 0.37 to $0.86, \mathrm{P}=0.009$ for trend). The association between dietary calcium and risk of primary hyperparathyroidism was similar for calcium intakes not adjusted for energy.

\section{Total calcium intake}

After adjusting for age, higher total daily intake of calcium (including dietary and supplemental calcium) was associated with a reduced risk of primary hyperparathyroidism (table 2). For women in the group with the highest intake of total calcium compared with women in the group with the lowest intake, the relative risk was 0.48 (95\% confidence interval 0.33 to 0.69 , $\mathrm{P}<0.001$ for trend), and the multivariable relative risk was 0.41 (0.27 to $0.63, \mathrm{P}<0.001$ for trend).

\section{Supplemental calcium intake}

We also studied the relation between supplemental calcium intake and risk of primary hyperparathyroidism. Because of an insufficient number of cases of primary hyperparathyroidism among the different categories of supplemental calcium use in the earlier time periods, our analysis on the relation between supplemental calcium intake and primary hyperparathyroidism began in 1994 with follow-up until 2008. During 985628 person years of follow-up over a 14 year period, we documented 257 cases of incident primary hyperparathyroidism.

Higher supplemental calcium intake was associated with a reduced risk of primary hyperparathyroidism (table $3 \Downarrow$ ). After adjusting for age, the relative risk for women taking more than $500 \mathrm{mg} /$ day of calcium supplements compared with those not taking calcium supplements was 0.69 (95\% confidence interval 0.50 to $0.94, \mathrm{P}<0.001$ for trend). The multivariable relative risk for the same comparison, including adjustment for dietary calcium, was 0.41 ( 0.29 to $0.60, \mathrm{P}<0.001$ for trend).

\section{Additional analyses}

Since cases of primary hyperparathyroidism can be incidentally detected after routine measurement of serum chemistry panels, ${ }^{35}$ we performed analyses with additional adjustment for having a physical exam (yes or no) during the prior two years of each time period in our multivariable analysis. The association between increased calcium intake and lower risk of primary hyperparathyroidism was similar after adjusting for regular physical exams, and was similar in analyses restricted to women who had a physical exam during the prior two years of each time period.

Since the incidence of primary hyperparathyroidism seems to increase with age ${ }^{36}{ }^{37}$ we also performed stratified analysis by age ( $\geq 65$ and $<65$ years). The association between increased calcium intake and reduced risk of primary hyperparathyroidism was similar in older and younger women $(\mathrm{P}=0.21$ for interaction); it was also similar after adjusting for menopausal status and use of postmenopausal hormone use. Since calcium absorption can depend on vitamin D status, we also performed analyses stratified by median total intake of vitamin D. The associations between higher calcium intake and decreased risk of primary hyperparathyroidism were similar among participants above and below this median level.

We also examined the association between cumulative calcium intake and risk of primary hyperparathyroidism, and the results were similar. Because we could not exclude the possibility that physicians stopped calcium supplements in participants with higher serum calcium concentrations shortly before primary hyperparathyroidism diagnosis, we also performed analyses with a four year lag between assessment of supplemental calcium use and primary hyperparathyroidism. In multivariable lag analyses, the relative risk of primary hyperparathyroidism was 0.79 (95\% confidence interval 0.57 to 1.09$)$ for women taking $1-500 \mathrm{mg} /$ day of supplemental calcium and $0.71(0.50$ to 1.00 ) for those taking more than $500 \mathrm{mg} /$ day of supplemental calcium, compared with women not taking supplemental calcium $(\mathrm{P}=0.12$ for trend $)$.

\section{Discussion}

To our knowledge, we report results from the first prospective study of the relation between calcium intake and risk of primary hyperparathyroidism. In women, increased dietary and supplemental calcium intake was associated with a reduced risk for developing primary hyperparathyroidism, independent of age, body size, diet, and other factors.

\section{Comparison with other studies}

Several studies have examined the effect of calcium intake in patients already diagnosed with primary hyperparathyroidism, with differing results. ${ }^{38-41}$ Insogna and colleagues ${ }^{39}$ found that calcium intake of $1000 \mathrm{mg} /$ day compared with $400 \mathrm{mg} /$ day suppressed the mean fasting level of parathyroid hormone by 19\% among 18 study participants with primary

hyperparathyroidism. Jorde and colleagues ${ }^{40}$ found that the level of parathyroid hormone decreased after four weeks in 17 of 24 participants with primary hyperparathyroidism who were given calcium supplementation. On the other hand, Locker and colleagues $^{41}$ found no significant effect of dietary calcium intake on serum parathyroid hormone level among 71 participants already diagnosed with primary hyperparathyroidism. However, no study has prospectively examined the association between calcium intake and risk of developing primary hyperparathyroidism.

\section{Limitations of the study}

There are several limitations to our study. Firstly, since our study population was female and almost entirely white, our findings are not necessarily generalizable to men or other races. Secondly, we cannot exclude selection bias. We only included cases confirmed by medical record review, and we could not obtain medical records for all women who self reported primary hyperparathyroidism. Thirdly, although the food frequency questionnaires have been well validated, calcium intake was not perfectly assessed in this study. However, because of the prospective design, any misclassification would be random with respect to case status, and therefore would probably underestimate the magnitude of the inverse association between calcium intake and risk of primary hyperparathyroidism. Fourthly, many cases of primary hyperparathyroidism may be asymptomatic and detected by routine blood work. However, 
in subanalyses restricted to women who had regular physical exams, the inverse relation between calcium intake and risk of developing primary hyperparathyroidism remained robust. Fifthly, since we conducted an observational study, there could be unknown confounders that we did not control for in our analysis. Finally, the magnitude of the association between higher supplemental calcium intake and lower risk of primary hyperparathyroidism was attenuated in lag analyses. Thus, we cannot exclude the possibility that some women with higher values of serum calcium on routine bloodwork were told to stop taking calcium supplements before their diagnosis of primary hyperparathyroidism.

\section{Areas for future research}

Calcium intake could have a role in the pathogenesis of primary hyperparathyroidism by influencing the production of parathyroid hormone. ${ }^{17-22}$ The monoclonal nature of the single parathyroid adenoma that causes the large majority of cases of primary hyperparathyroidism ${ }^{13-15}$ suggests a neoplasm that originates from single cells with a growth-conferring mutation. Because factors that cause parathyroid hyperplasia, such as lower calcium intake, increase the probability that a parathyroid cell will undergo a somatic mutation and subsequent clonal proliferation, such factors could increase the risk for developing primary hyperparathyroidism. ${ }^{11416}$ The peak disease incidence occurring later in life also suggests that risk factors for primary hyperparathyroidism could be due to a chronic stimulus over time. ${ }^{42}$ Future research should examine other environmental and lifestyle risk factors that could chronically stimulate the parathyroid gland and thereby affect subsequent development of primary hyperparathyroidism.

We thank the participants in the Nurses' Health Study for their continuing cooperation. An abstract of this work was presented at the annual meeting of the American Society of Bone and Mineral Research on 19 September 2011

Contributors: JP is the guarantor and takes responsibility for the integrity of the work as a whole, from inception to publication; contributed to the study conception and design, acquisition of data, analysis, interpretation of data, and drafting of the article; and approved the final version of the manuscript. GC contributed to the conception and design, interpretation of data, critical revisions of the article, and approved the final version of the manuscript. ET contributed to the conception and design, acquisition of data, interpretation of data, critical revisions of the article, and approved the final version of the manuscript.

Funding: This research was supported by the US National Institutes of Health grants DK084707, HL092947, DK91417, and CA087969.

Competing interests: All authors have completed the Unified Competing Interest form at www.icmje.org/coi_disclosure.pdf (available on request from the corresponding author) and declare: support from the US National Institutes of Health; no financial relationships with any organizations that might have an interest in the submitted work in the previous 3 years; no other relationships or activities that could appear to have influenced the submitted work.

Ethical approval: The institutional review board at the Brigham and Women's Hospital approved this study.

Data sharing: Requests for access to data, statistical code, questionnaires, and technical processes may be made by contacting the corresponding author at jmpaik@partners.org.

Marcocci C, Cetani F. Clinical practice. Primary hyperparathyroidism. N Engl J Med 2011:365:2389-97.

$2 \mathrm{NIH}$ conference. Diagnosis and management of asymptomatic primary hyperparathyroidism: consensus development conference statement. Ann Intern Med 1991;114:593-7
3 Jorde R, Bonaa KH, Sundsfjord J. Primary hyperparathyroidism detected in a health screening: the Tromso study J Clin Epidemiol 2000:53:1164-9.

4 Lundgren E, Hagstrom EG, Lundin J, Winnerback K, Roos J, Ljunghall S, et al. Primary hyperparathyroidism revisited in menopausal women with serum calcium in the upper normal range at population-based screening 8 years ago. World J Surg 2002;26:931-6.

5 Ruda JM, Hollenbeak CS, Stack BC Jr. A systematic review of the diagnosis and treatment of primary hyperparathyroidism from 1995 to 2003. Otolaryngol Head Neck Surg 2005:132:359-72.

6 Wermers RA, Khosla S, Atkinson EJ, Hodgson SF, O'Fallon WM, Melton LJ. The rise and fall of primary hyperparathyroidism: a population-based study in Rochester, Minnesota, 1965-1992. Ann Intern Med 1997;126:433-40

7 Rubin MR, Bilezikian JP, McMahon DJ, Jacobs T, Shane E, Siris E, et al. The natural history of primary hyperparathyroidism with or without parathyroid surgery after 15 years. I Clin Endocrinol Metab 2008:93:3462-70.

8 Silverberg S, Shane E, Jacobs T, Siris E, Bilezikian J. A 10-year prospective study of primary hyperparathyroidism with or without parathyroid surgery. N Engl J Med 1999;341:1249-55

9 Bilezikian J, Silverberg S. Clinical spectrum of primary hyperparathyroidism. Rev Endocr Metab Disord 2000;1:237-45

10 Arnold A, Kim HG, Gaz RD, Eddy RL, Fukushima Y, Byers MG, et al. Molecular cloning and chromosomal mapping of DNA rearranged with the parathyroid hormone gene in a parathyroid adenoma. J Clin Invest 1989;83:2034-40.

11 Miedlich S, Krohn K, Paschke R. Update on genetic and clinical aspects of primary hyperparathyroidism. Clin Endocrinol (Oxf) 2003;59:539-54.

12 Beard CM, Heath H 3rd, O'Fallon WM, Anderson JA, Earle JD, Melton LJ 3rd. Therapeutic radiation and hyperparathyroidism. A case-control study in Rochester, Minn. Arch Intern Med 1989;149:1887-90.

13 Arnold A, Staunton CE, Kim HG, Gaz RD, Kronenberg HM. Monoclonality and abnormal parathyroid hormone genes in parathyroid adenomas. N Engl J Med 1988;318:658-62.

14 Shan L, Nakamura M, Nakamura Y, Inoue D, Morimoto S, Yokoi T, et al. Comparative analysis of clonality and pathology in primary and secondary hyperparathyroidism. Virchows Arch 1997:430:247-51.

15 Miedlich S, Krohn K, Lamesch P, Muller A, Paschke R. Frequency of somatic MEN1 gene mutations in monoclonal parathyroid tumours of patients with primary hyperparathyroidism. Eur J Endocrinol 2000;143:47-54

16 Arnold A, Brown M, Ureña P, Gaz R, Sarfati E, Drüeke T. Monoclonality of parathyroid tumors in chronic renal failure and in primary parathyroid hyperplasia. J Clin Invest 1995;95:2047-53.

17 McKane WR, Khosla S, Egan KS, Robins SP, Burritt MF, Riggs BL. Role of calcium intake in modulating age-related increases in parathyroid function and bone resorption. $J$ Clin Endocrinol Metab 1996;81:1699-703.

18 Tordoff M, Hughes R, Pilchak D. Calcium intake by rats: influence of parathyroid hormone, calcitonin, and 1,25-dihydroxyvitamin D. Am J Physiol 1998;274:R214-31.

19 Naveh-Many T, Friedlaender M, Mayer H, Silver J. Calcium regulates parathyroid hormone messenger ribonucleic acid (mRNA), but not calcitonin mRNA in vivo in the rat. Dominant role of 1,25-dihydroxyvitamin D. Endocrinology 1989;125:275-80.

20 Naveh-Many T, Rahamimov R, Livni N, Silver J. Parathyroid cell proliferation in normal and chronic renal failure rats. The effects of calcium, phosphate, and vitamin D. J Clin Invest 1995;96:1786-93.

21 Karp H, Ketola M, Lamberg-Allardt C. Acute effects of calcium carbonate, calcium citrate and potassium citrate on markers of calcium and bone metabolism in young women. $\mathrm{Br}$ J Nutr 2009;102:1341-7.

22 Kanesaka Y, Tokunaga H, Iwashita K, Fujimura S, Naomi S, Tomita K. Endothelin receptor antagonist prevents parathyroid cell proliferation of low calcium diet-induced hyperparathyroidism in rats. Endocrinology 2001;142:407-13.

23 Willett W, Sampson L, Stampfer M, Rosner B, Bain C, Witschi J, et al. Reproducibility and validity of a semiquantitative food frequency questionnaire. Am J Epidemiol 1985;122:51-65

24 Salvini S, Hunter D, Sampson L, Stampfer M, Colditz G, Rosner B, et al. Food-based validation of a dietary questionnaire: the effects of week-to-week variation in food consumption. Int J Epidemiol 1989;18:858-67.

25 Rimm E, Stampfer M, Colditz, GA, Chute C, Litin L, Willett W. Validity of self-reported waist and hip circumference in men and women. Epidemiology 1990;1:466-73.

26 Wolf A, Hunter D, Colditz G, Manson J, Stampfer M, Corsano K, et al. Reproducibility and validity of a self-administered physical activity questionnaire. Int J Epidemiol 1994;23:991-9.

27 Colditz GA, Martin P, Stampfer MJ, Willett WC, Sampson L, Rosner B, et al. Validation of questionnaire information on risk factors and disease outcomes in a prospective cohort study of women. Am J Epidemiol 1986;123:894-900.

28 Manson JE, Colditz GA, Stampfer MJ, Willett WC, Krolewski AS, Rosner B, et al. A prospective study of maturity-onset diabetes mellitus and risk of coronary heart disease and stroke in women. Arch Intern Med 1991;151:1141-7.

29 Colditz GA, Stampfer MJ, Willett WC, Stason WB, Rosner B, Hennekens CH, et al. Reproducibility and validity of self-reported menopausal status in a prospective cohor study. Am J Epidemiol 1987:126:319-25.

30 Lundgren E, Rastad J, Thrufjell E, Akerström G, Ljunghall S. Population-based screening for primary hyperparathyroidism with serum calcium and parathyroid hormone values in menopausal women. Surgery 1997;121:287-94.

31 Kao P, van Heerden J, Grant C, Klee G, Khosla S. Clinical performance of parathyroid hormone immunometric assays. Mayo Clin Proc 1992:67:637-45.

32 Ljunghall S, Larsson K, Lindh E, Lindqvist U, Rastad J, Akerström G, et al. Disturbance of basal and stimulated serum levels of intact parathyroid hormone in primary hyperparathyroidism. Surgery 1991;110:47-53.

33 Rutledge R, Stiegel M, Thomas C Jr, Wild R. The relation of serum calcium and immunoparathormone levels to parathyroid size and weight in primary hyperparathyroidism. Surgery 1985;98:1107-12.

34 Norman J, Goodman A, Politz D. Calcium, parathyroid hormone, and vitamin D in patients with primary hyperparathyroidism: normograms developed from 10,000 cases. Endocrine Practice 2011;17:384-94.

35 Melton LJ. The epidemiology of primary hyperparathyroidism in North America. J Bone Miner Res 2002;17(suppl 2):N12-7.

36 Wermers RA, Khosla S, Atkinson EJ, Achenbach SJ, Oberg AL, Grant CS, et al. Incidence of primary hyperparathyroidism in Rochester, Minnesota, 1993-2001: an update on the changing epidemiology of the disease. J Bone Miner Res 2006:21:171-7. 


\section{What is already known on this topic}

Calcium intake is known to influence parathyroid hormone levels and therefore could be important in the pathogenesis of primary hyperparathyroidism

No study to date has prospectively explored the relation between calcium intake and risk of developing primary hyperparathyroidism

\section{What this study adds}

Increased calcium intake, including both dietary and supplemental calcium, is independently associated with a reduced risk of developing primary hyperparathyroidism in women

37 Miller BS, Dimick J, Wainess R, Burney RE. Age- and sex-related incidence of surgically treated primary hyperparathyroidism. World J Surg 2008;32:795-9.

38 Dent CE, Hartland BV, Hicks J, Sykes ED. Calcium intake in patients with primary hyperparathyroidism. Lancet 1961;2:336-8.

39 Insogna KL, Mitnick ME, Stewart AF, Burtis WJ, Mallette LE, Broadus AE. Sensitivity of the parathyroid hormone-1,25-dihydroxyvitamin $D$ axis to variations in calcium intake in patients with primary hyperparathyroidism. N Engl J Med 1985;313:1126-30.

40 Jorde R, Szumlas K, Haug E, Sundsfjord J. The effects of calcium supplementation to patients with primary hyperparathyroidism and a low calcium intake. Eur J Nutr 2002;41:258-63.

41 Locker FG, Silverberg SJ, Bilezikian JP. Optimal dietary calcium intake in primary hyperparathyroidism. Am J Med 1997;102:543-50.
42 Shelby H. Age and sex-related incidence of primary hyperparathyroidism. World J Surg 2008;32:800.

Accepted: 10 September 2012

Cite this as: BMJ 2012;345:e6390

This is an open-access article distributed under the terms of the Creative Commons Attribution Non-commercial License, which permits use, distribution, and reproduction in any medium, provided the original work is properly cited, the use is non commercial and is otherwise in compliance with the license. See: http://creativecommons.org/licenses/bync/2.0/ and http://creativecommons.org/licenses/by-nc/2.0/legalcode. 


\section{Tables}

\begin{tabular}{|c|c|c|c|c|c|}
\hline & \multicolumn{5}{|c|}{ Dietary calcium intake } \\
\hline & Group $1(n=11490)$ & Group $2(n=11$ 808) & Group $3(n=11$ 818) & Group $4(n=11740)$ & Group 5 ( $n=11$ 498) \\
\hline Age (years) ${ }^{*}$ & 51.3 & 51.4 & 51.7 & 51.8 & 52.4 \\
\hline Body mass index & 25.0 & 25.1 & 25.2 & 25.3 & 25.2 \\
\hline Physical activity (MET/week) & 11.9 & 13.9 & 14.6 & 15.4 & 16.1 \\
\hline Dietary calcium intake $(\mathrm{mg} /$ day $) \dagger$ & 431 & 564 & 672 & 811 & 1115 \\
\hline Calcium supplement intake (mg/day) & 352 & 351 & 360 & 357 & 335 \\
\hline Calcium supplement use (\% (No)) & $55(6351)$ & $56(6654)$ & $58(6833)$ & $58(6775)$ & $55(6370)$ \\
\hline $\begin{array}{l}\text { Total (dietary and supplemental) vitamin } \\
\text { D intake (IU/day) } \dagger\end{array}$ & 254 & 287 & 322 & 366 & 465 \\
\hline Magnesium intake (mg/day) $\dagger$ & 265 & 285 & 300 & 314 & 334 \\
\hline Total protein intake (gm/day) $\dagger$ & 70.1 & 72.5 & 74.4 & 76.8 & 81.3 \\
\hline Animal protein intake $(\mathrm{gm} / \mathrm{day}) \dagger$ & 50.3 & 51.7 & 53.5 & 56.2 & 62.1 \\
\hline $\begin{array}{l}\text { Total (dietary and supplemental) vitamin } \\
\text { A intake (mcg/day) } \dagger\end{array}$ & 1842 & 2051 & 2205 & 2329 & 2493 \\
\hline Alcohol intake (gm/day) & 8.8 & 6.7 & 5.8 & 5.0 & 4.0 \\
\hline \multicolumn{6}{|l|}{ Smoking status (\% (No)) } \\
\hline Never smoker & $43(4955)$ & $46(5374)$ & $46(5458)$ & $47(5470)$ & $50(5760)$ \\
\hline Past smoker & $33(3776)$ & $34(4068)$ & $37(4358)$ & $37(4375)$ & $35(4052)$ \\
\hline Current smoker & $24(2758)$ & $20(2366)$ & $17(2002)$ & $16(1895)$ & $15(1686)$ \\
\hline Self reported diabetes $(\%(\mathrm{No}))$ & $2(247)$ & $2(258)$ & $2(281)$ & $3(349)$ & $3(352)$ \\
\hline Self reported hypertension $(\%(\mathrm{No}))$ & $24(2722)$ & $22(2620)$ & $22(2615)$ & $23(2648)$ & $22(2584)$ \\
\hline Thiazide use (\% (No)) $\ddagger$ & $13(1517)$ & $12(1392)$ & $12(1459)$ & $12(1450)$ & $12(1374)$ \\
\hline Loop diuretic use (\% (No))§ & $1(171)$ & $2(181)$ & $2(195)$ & $1(171)$ & $2(196)$ \\
\hline
\end{tabular}

Data are mean values, or the percentages (and numbers) of participants that are standardized to the age distribution of the study population. Study population divided into five equal groups according to intake of dietary calcium. MET=metabolic equivalent task scores.

*Not adjusted by age.

†Energy adjusted.

†From 1988.

§From 1994 


\begin{tabular}{|c|c|c|c|c|c|c|}
\hline & Group 1 & Group 2 & Group 3 & Group 4 & Group 5 & P for trend \\
\hline \multicolumn{7}{|l|}{ Dietary calcium intake } \\
\hline $\begin{array}{l}\text { Median within group } \\
\text { (mg/day) }\end{array}$ & 443 & 564 & 670 & 806 & 1070 & - \\
\hline $\begin{array}{l}\text { No of cases of primary } \\
\text { hyperparathyroidism }\end{array}$ & 69 & 57 & 57 & 50 & 44 & - \\
\hline No of person years & 290985 & 296872 & 298068 & 297109 & 292944 & - \\
\hline $\begin{array}{l}\text { Age adjusted relative risk } \\
(95 \% \mathrm{Cl})\end{array}$ & 1.0 & 0.81 (0.57 to 1.15$)$ & $0.80(0.56$ to 1.14$)$ & $0.70(0.49$ to 1.01$)$ & $0.61(0.42$ to 0.90$)$ & 0.03 \\
\hline $\begin{array}{l}\text { Multivariable relative risk } \\
(95 \% \mathrm{Cl}) \dagger\end{array}$ & 1.0 & 0.79 (0.55 to 1.13$)$ & $0.78(0.54$ to 1.11$)$ & $0.66(0.45$ to 0.98$)$ & $0.56(0.37$ to 0.86$)$ & 0.009 \\
\hline \multicolumn{7}{|l|}{ Total calcium intake } \\
\hline $\begin{array}{l}\text { Median within group } \\
\text { (mg/day) }\end{array}$ & 522 & 737 & 999 & 1276 & 1794 & - \\
\hline $\begin{array}{l}\text { No of cases of primary } \\
\text { hyperparathyroidism }\end{array}$ & 86 & 61 & 43 & 42 & 45 & - \\
\hline No of person years & 289554 & 294850 & 297322 & 298933 & 295321 & - \\
\hline $\begin{array}{l}\text { Age adjusted relative risk } \\
(95 \% \mathrm{Cl})\end{array}$ & 1.0 & 0.69 (0.50 to 0.96$)$ & $0.48(0.33$ to 0.69$)$ & $0.45(0.31$ to 0.65$)$ & $0.48(0.33$ to 0.69$)$ & $<0.001$ \\
\hline $\begin{array}{l}\text { Multivariable relative risk } \\
(95 \% \mathrm{Cl}) \ddagger\end{array}$ & 1.0 & 0.64 (0.46 to 0.91$)$ & $0.42(0.28$ to 0.62$)$ & $0.39(0.25$ to 0.58$)$ & $0.41(0.27$ to 0.63$)$ & $<0.001$ \\
\hline
\end{tabular}

Population divided into five equal groups according to intake of calcium.

*For illustrative purposes, medians within each group for intake of dietary and total calcium were derived from responses to the 1986 dietary questionnaire. However, the period specific medians were used for the 1986-2008 analysis. Relative risks are for the risk of primary hyperparathyroidism compared with the group that had the lowest intake of dietary or total calcium (that is, group 1).

†Multivariable model includes age, body mass index (categories: <22, 22-24.9, 25-29.9, $\geq 30$ ), race, smoking status (past, current, or never), calcium supplement intake, total vitamin D intake, dietary intakes of vitamin A and protein, alcohol intake, and diuretic use (thiazide or loop diuretic use).

¥Multivariable model includes age, body mass index (categories: $<22,22-24.9,25-29.9, \geq 30$ ), race, smoking status (past, current, or never), total vitamin $D$ intake, dietary intakes of vitamin A and protein, alcohol intake (categories: none, 0.1-4.9, 5-14.9, $\geq 15 \mathrm{~g} /$ day), and diuretic use (thiazide or loop diuretic use). 
Table 3| Age adjusted and multivariable relative risks for incident primary hyperparathyroidism according to supplemental calcium intake

\begin{tabular}{lcccc} 
& \multicolumn{3}{c}{ Supplemental calcium intake (mg/day) } & P for trend \\
\cline { 2 - 5 } & None & $\mathbf{1 - 5 0 0}$ & $\mathbf{5 0 0}$ & - \\
$\begin{array}{l}\text { No of cases of primary } \\
\text { hyperparathyroidism }\end{array}$ & 85 & 86 & 86 & - \\
\hline No of person years & 294279 & 293762 & 397587 & $<0.001$ \\
\hline Age adjusted relative risk $(95 \% \mathrm{Cl})$ & 1.0 & $0.99(0.73$ to 1.34$)$ & $0.69(0.50$ to 0.94$)$ & $<0.001$ \\
\hline Multivariable relative risk $(95 \% \mathrm{Cl}) \dagger$ & 1.0 & $0.82(0.59$ to 1.15$)$ & $0.41(0.29$ to 0.60$)$ &
\end{tabular}

${ }^{\star}$ Follow-up started in 1994 because of insufficient number of cases of primary hyperparathyroidism in participants taking supplemental calcium from 1984-93. †Multivariable model includes: age, body mass index (categories: $<22,22-24.9,25-29.9, \geq 30$ ), race, smoking status (past, current, never), dietary calcium intake, total vitamin $D$ intake, dietary intakes of vitamin $A$ and protein, alcohol intake (categories: none, $0.1-4.9,5-14.9, \geq 15 \mathrm{~g} /$ day), and diuretic use (thiazide or loop diuretic use). 